\title{
Response to letter to the editor (NRAD-13-78) Re: Variations in the origin of the vertebral artery and its level of entry into the transverse foramen diagnosed by $\mathrm{CT}$ angiography Dan Meila; Marcin Tysiac; Friedhelm Brassel
}

\author{
Akira Uchino \\ Received: 22 February 2013 / Accepted: 4 March 2013 /Published online: 9 May 2013 \\ (C) Springer-Verlag Berlin Heidelberg 2013
}

Dear Sir,

We thank Dr. Meila and colleagues for their valuable comments. We agree that we missed their paper [1], which was published just before the submission of our paper [2]. Our article was written after a careful literature search at a time when their paper was not yet online. Unfortunately, we did not repeat the literature search when revising our paper. It is noteworthy that the two reviewers were not aware of their article. We sincerely apologize to Dr. Meila and colleagues for our incomplete review of the literature and are happy we can bring their article to the attention of the readers of Neuroradiology in this way.

In regard to the scientific issue Dr. Meila raises, we understand they presented a case of duplicate origin of the left vertebral artery with both branches arising from the aortic arch directly. Our double aortic arch model cannot explain this extremely rare variation. Thus, we agree with their opinion that variations of the vertebral artery system can occur at nearly any level.
Again, we repeat our apologies and hope that Dr Meila and his co-authors may accept them.

Conflict of interest I declare that I have no conflict of interest.

\section{References}

1. Meila D, Tysiac M, Petersen M, Theisen O, Wetter A, Mangold A, Schlunz-Hendann M, Papke K, Brassel F, Berenstein A (2012) Origin and course of the extracranial Vertebral Artery - CTA findings, association with vascular lesions and embryologic considerations. Clin Neuroradiol 22(4):327-33. doi:10.1007/s00062-0120171-0

2. Uchino A, Saito N, Takahashi M, Okada Y, Kozawa E, Nishi N, Mizukoshi W, Nakajima R, Watanabe Y (2013) Variations in the origin of the vertebral artery and its level of entry into the transverse foramen diagnosed by CT angiography. Neuroradiology. doi:10.1007/s00234-013-1142-0
This reply refers to the comment available at DOI $10.1007 / \mathrm{s} 00234-$ 013-1161-x.

\section{A. Uchino $(\square)$}

Department of Diagnostic Radiology,

Saitama Medical University International Medical Center,

1397-1 Yamane, Hidaka,

Saitama 350-1298, Japan

e-mail: auchino@saitama-med.ac.jp 